\title{
Preparation of Stable Microemulsions with Different Droplet Size
}

\author{
Hu Shiyu, Chen Jiaxuan, Zhu Yeting, Wei Yelu, Di Tongtong, Shen Hangyan* \\ College of Materials and Chemistry, China Jiliang University, Hangzhou, China \\ Email address: \\ hsy1998520@sina.com (Hu Shiyu),690792408@qq.com (Chen Jiaxuan),351085622@qq.com (Zhu Yeting), \\ 1798449167@qq.com (Wei Yelu),1329253785@qq.com (Di Tongtong), shenhangyan@ cjlu.edu.cn (Shen Hangyan) \\ *Corresponding author
}

To cite this article:

Hu Shiyu, Chen Jiaxuan, Zhu Yeting, Wei Yelu, Di Tongtong, Shen Hangyan. Preparation of Stable Microemulsions with Different Droplet Size. American Journal of Nanosciences. Vol. 5, No. 4, 2019, pp. 76-82. doi: 10.11648/j.ajn.20190504.18

Received: November 7, 2019; Accepted: November 28, 2019; Published: December 10, 2019

\begin{abstract}
Microemulsion is a widely used technique for preparing nanoparticles. The droplet size in stable microemulsions is a key parameter for limiting the size and shape of the formed nanoparticles. In this paper, the stable microemulsions were synthesized by two titration methods, the water titration method and the co-surfactant titration. Six reagents with different HLB were used as surfactants, including Span-80, E-1302, EL-10, MOA-9, Triton X-114 and OP-10. Quasi ternary phase diagrams of O/W and W/O microemusions with different surfactants were established according to the composition of surfactant, co-surfactant, oil and water. The size of the microemulsions droplets was characterized by using Zetasizer Nano S90. Within the stable micromulsions region, the droplet size was systemically controlled from $1 \mathrm{~nm}$ to $120 \mathrm{~nm}$ by changing different surfactants and controlling the quality ratio of components. A complex dependence of the droplet size on the water to surfactant ratio and the co-surfactant to surfactant ratio was established. In the stable microemulsions region, the droplets size increases dramatically with increased the water to surfactant ratio and the larger droplet size is obtained with increasing the co-surfactant amount.
\end{abstract}

Keywords: Microemulsions, Quasi Ternary Phase, Droplet Size

\section{Introduction}

Microemulsions have wide applications in the nanomaterials [1, 2], surface science [3], magnetic field [4], cosmetic [5, 6], pharmaceutical industries [7, 8], and so on. Microemulsions are thermodynamically stable colloidal dispersions of two immiscible liquids (typically water and oil) that coexist in one phase due to the presence of surfactant and co-surfactant molecules with balanced hydrophilic-lipophilic properties [9]. The successful preparation of the microemulsions has a strict requirement for the proportions of the ingredients, whereas the selection and design of the microemulsions composition is complex, time-consuming and unpredictable. Owing to the different compositions having different stable ranges of the microemulsions system, it is necessary to study the stability region of the microemulsions system for the wider use [10].

Microemulsion is a widely used technique for preparing nanoparticles with better control of size, shape and size distribution [11-14]. In the presence of surfactants, stable microemusions consisting of nanometer-sized $\mathrm{H}_{2} \mathrm{O}$ droplets dispersed in oil or nanometer-sized oil droplets dispersed in water. As a consequence, the droplet can act as a small reactor to confine the nuclei growth and hinder inter-gain agglomeration. The size of the droplet is a key parameter for limiting the size and shape of the formed nanoparticles. By varying primary parameters, such as water to oil ratio, surfactant and co-surfactant concentration, the size of droplet varies from a few nanometers to a few hundred nanometers [15].

The aim of this work was to provide a widely available microemulsions preparation formulation by using different surfactants and controlling the ratio of components. The quasi ternary phase diagrams of stable microemulsions with different surfactants were mapped. Then the effects of the water-to-surfactant ratio and surfactant-to-co-surfactant ratio on the droplet size were investigated. 


\section{Material and Methods}

Six reagents with different HLB (Hydrophile Lipophilic Balance) were used as surfactants, including Span-80 $\left(\mathrm{C}_{24} \mathrm{H}_{44} \mathrm{O}_{6}, \quad \mathrm{HLB}=4.5\right), \quad \mathrm{E}-1302 \quad\left(\mathrm{RO} \quad\left(\mathrm{CH}_{2} \mathrm{CH}_{2} \mathrm{O}\right)_{\mathrm{n}} \mathrm{H}\right.$, $\mathrm{HLB}=5-6)$, Cremphor EL-10 (HLB=6.4), MOA-9 $\left(\mathrm{C}_{12} \mathrm{H}_{25} \mathrm{O}\right.$ $\left.\left(\mathrm{C}_{2} \mathrm{H}_{4} \mathrm{O}\right)_{\mathrm{n}}, \mathrm{HLB}=12.5\right)$, Triton $\mathrm{X}-114\left(\mathrm{C}_{18} \mathrm{H}_{30} \mathrm{O}_{3}, \mathrm{HLB}=13.5\right)$, OP-10 $\left(\mathrm{C}_{34} \mathrm{H}_{62} \mathrm{O}_{11}, \mathrm{HLB}=14.5\right)$. Cyclohexane $\left(\mathrm{C}_{6} \mathrm{H}_{12}\right.$, purity $\geq 99.7 \%$ ) was used as oil. Isopropanol $\left(\mathrm{C}_{3} \mathrm{H}_{8} \mathrm{O}\right.$, purity $\geq$ $99.7 \%$ ) was used as co-surfactant.

Microemulsions were synthesized by the water titration method. The amount of surfactant, co-surfactant and oil were mixed under vigorous stirring in room temperature $\left(24^{\circ} \mathrm{C}\right.$ $\sim 27^{\circ} \mathrm{C}$ ) to form the transparent solution. Then the deionized water was added dropwise into the mixed solution to form the microemulsion. The thermodynamically stable microemulsion

\section{Results and Discussion}

\subsection{Quasi Ternary Phase Diagrams of the Microemulsions}
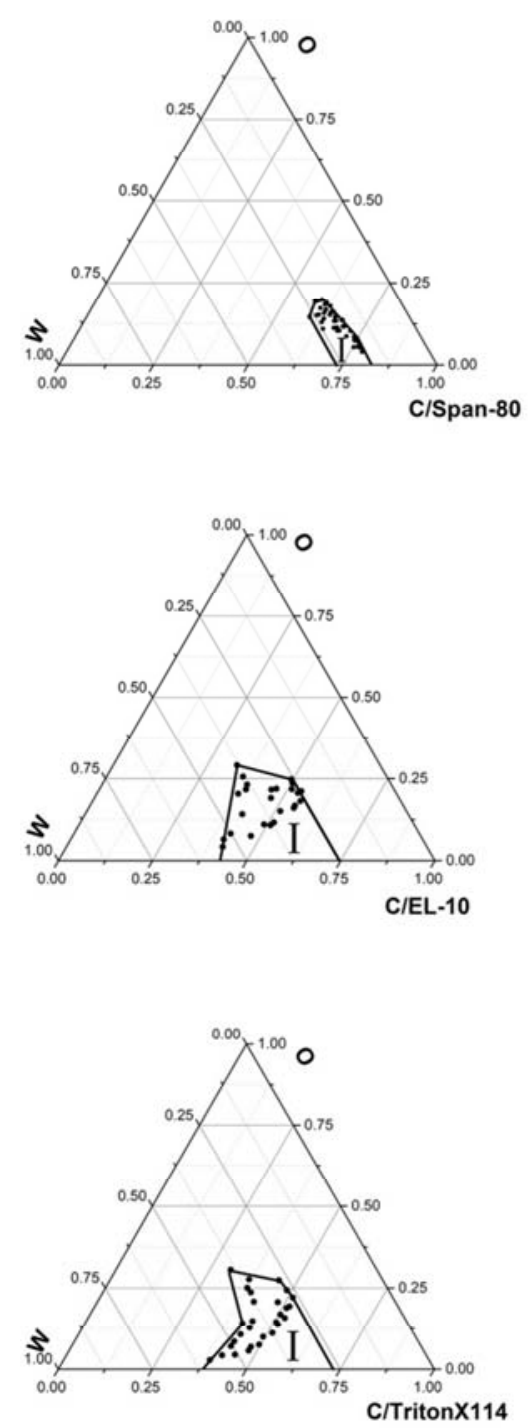

was transparent. As the solution changed from clear to turbid and stood for ten minutes, the microemulsion vanished. The composition at this transition point was recorded.

Microemulsions were also synthesized by co-surfactant titration method. The mixed solution of surfactant, oil and water was turbid. Co-surfactant was added into the solution to observe the transparency variation of the system. As the solution changed from turbid to clear and stood for ten minutes, the microemulsion formed and the amount of each component at this transition point was recorded.

Quasi ternary phase diagrams with different surfactants were established according to the composition at the transition point recorded above. The size and size distribution of microemulsions droplets were determined by Zetasizer Nano S90 (Malvern Instruments Ltd, UK). The microemulsion was directly used in the test without any dilution.
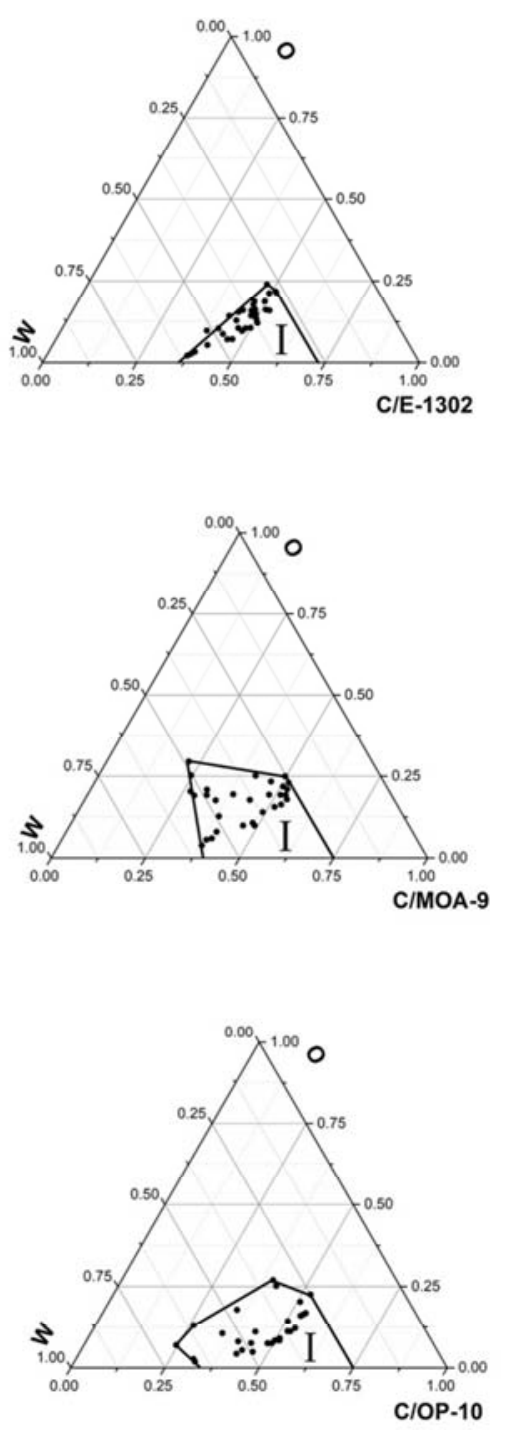

Figure 1. Quasi ternary phase diagrams of $\mathrm{O} / \mathrm{W}$ microemulsions. 
According to the ratio of water to oil, the microemulaions can be divided into the $\mathrm{O} / \mathrm{W}$ (oil dispersed in water) and $\mathrm{W} / \mathrm{O}$ microemusions (reverse micelles, water dispersed in oil). Figure 1 are quasi phase diagrams of $\mathrm{O} / \mathrm{W}$ microemulsions using Span-80, E-1302, EL-10, MOA-9, TritonX-114 and OP-10 as surfactant respectively. Within the monophasic region $\mathrm{I}$, the stable microemulsion can be existed. It is obviously that surfactant system with high HLB possesses the wide stable microemulsion region. The area of the stable microemulsion region increases with the increasing of HLB
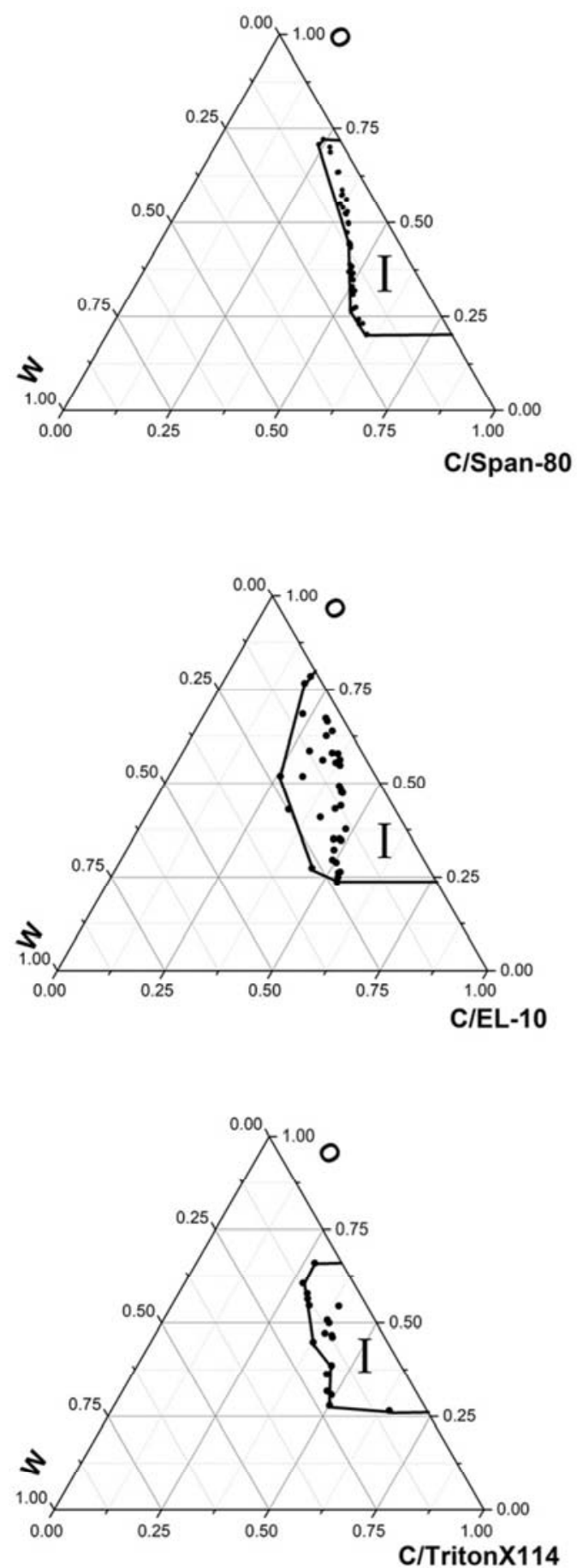

from 4 to 12 and keeps similar after that. Surfactants with high HLB value are preferred for $\mathrm{O} / \mathrm{W}$ microemulsions $[3,16]$, thus could greatly enhance the maximum oil content. Figure 2 represents the quasi ternary phase diagrams of $\mathrm{W} / \mathrm{O}$ microemulsions with different surfactants. Very small area of the stable microemulsions is obtained for the diagrams of Span-80, which has the lowest HLB value. No obviously difference in the monophasic region area is observed for the other surfactants.
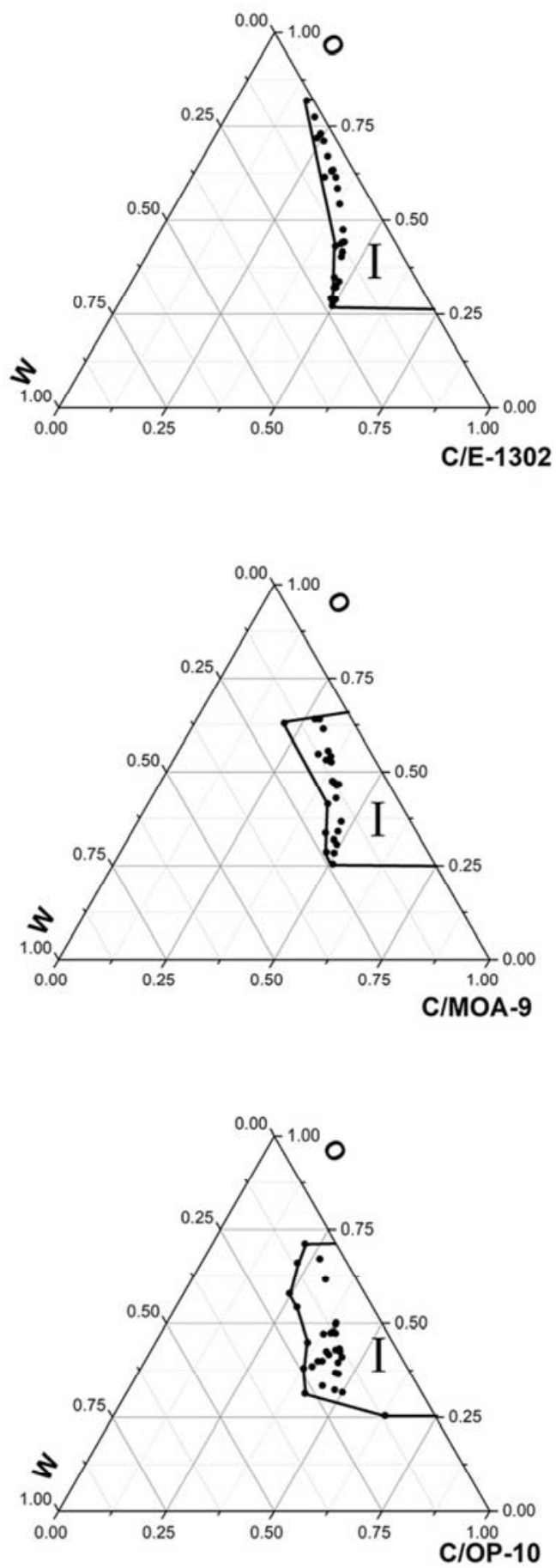

Figure 2. Quasi ternary phase diagrams of W/O microemulsions. 


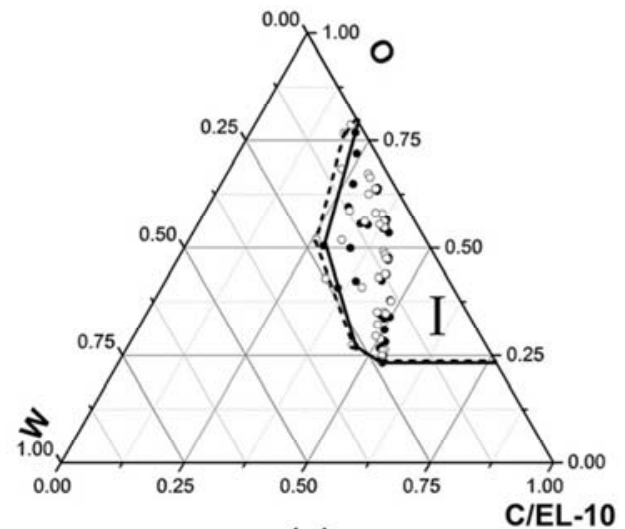

(a)

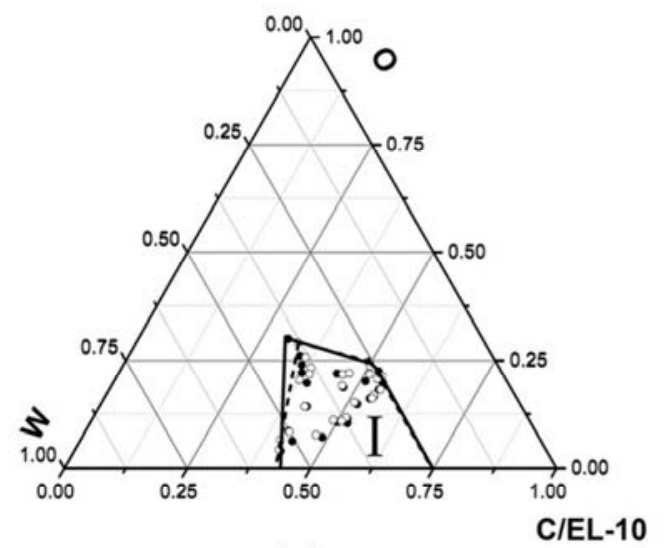

(c)

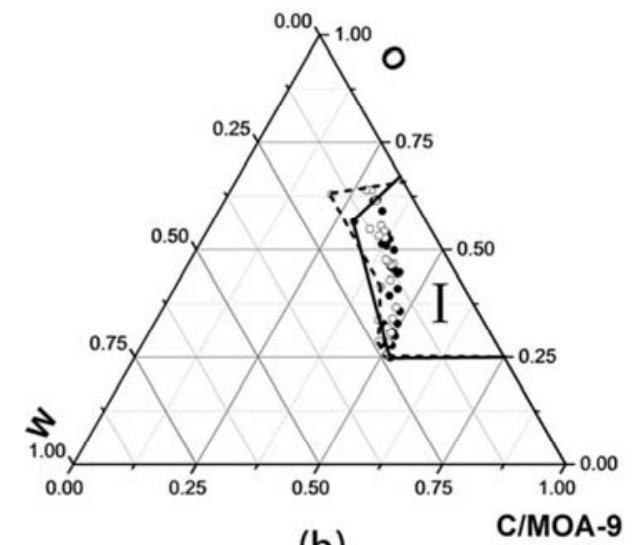

(b)

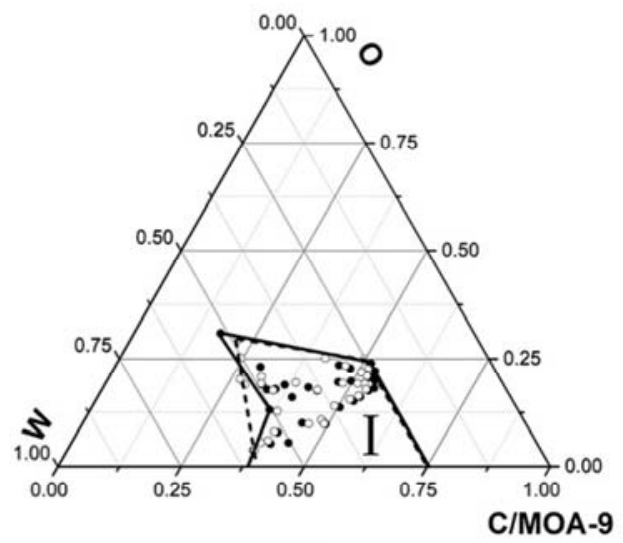

(d)

Figure 3. Quasi ternary phase diagrams of $W / O(a, b)$ and $O / W(c, d)$ microemulsions using different titrant methods.

Figure 3 shows quasi ternary phase diagrams of W/O (a, b) and $\mathrm{O} / \mathrm{W}$ (c, d) microemulsions obtained by using different titrant, the dotted line is constructed using the water titration method and the solid line is constructed using the co-surfactant titration method. As shown in Figure 3, microemulsions areas are almost coincident with different titrants which proved that the different titrant method has little influence on the formation of microemulsions.

\subsection{Microemulsions Droplets Size Analysis}

Figure 4 shows size distributions of W/O microemulsions droplets under different quality ratio of water to surfactant using Span-80, E-1302, EL-10, MOA-9, TritonX-114 and OP-10 as surfactant respectively. The ratio of surfactant to co-surfactant and oil is kept constant as 1: 6: 4, while the water-to-surfactant ratio is varied by changing the $\mathrm{X}$ from 0.8 to the maximum water solubilization, which is the emulsification boundary value. The stable microemulsions will disappear beyond this value. It can be seen that the narrow size distribution is obtained and the droplet size increases with increasing the quality ratio of water to surfactant.
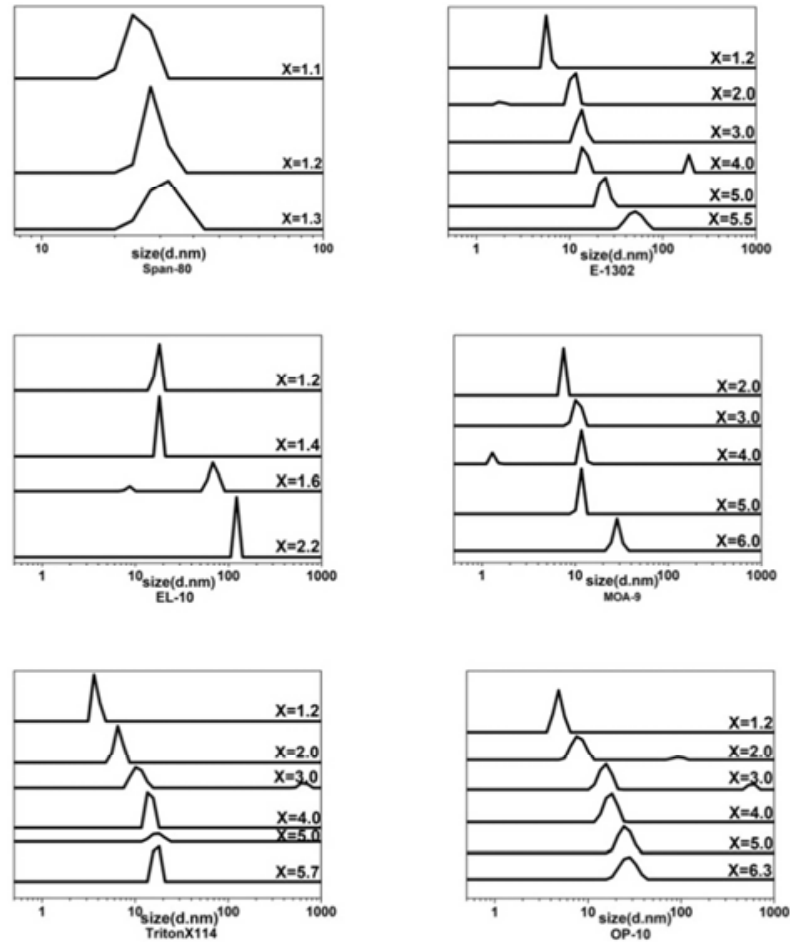

Figure 4. Size distributions of W/O microemulsions droplets under different quality ratio of water. 
Figure 5 shows size distributions of $\mathrm{O} / \mathrm{W}$ microemulsions droplets under variable surfactants and water to surfactant ratios. The ratio of surfactant to co-surfactant and oil is kept constant as 1: 5: 1, while the water-to-surfactant ratio is varied. Similar results are obtained as that of $\mathrm{W} / \mathrm{O}$ microemulsions.

With different surfactants, the effect of water to surfactant ratio on the microemulsions droplet size is shown in Figure 6, (a) and (b) represents the $\mathrm{W} / \mathrm{O}$ and $\mathrm{O} / \mathrm{W}$ micromulsions respectively. It is found that the droplet size of
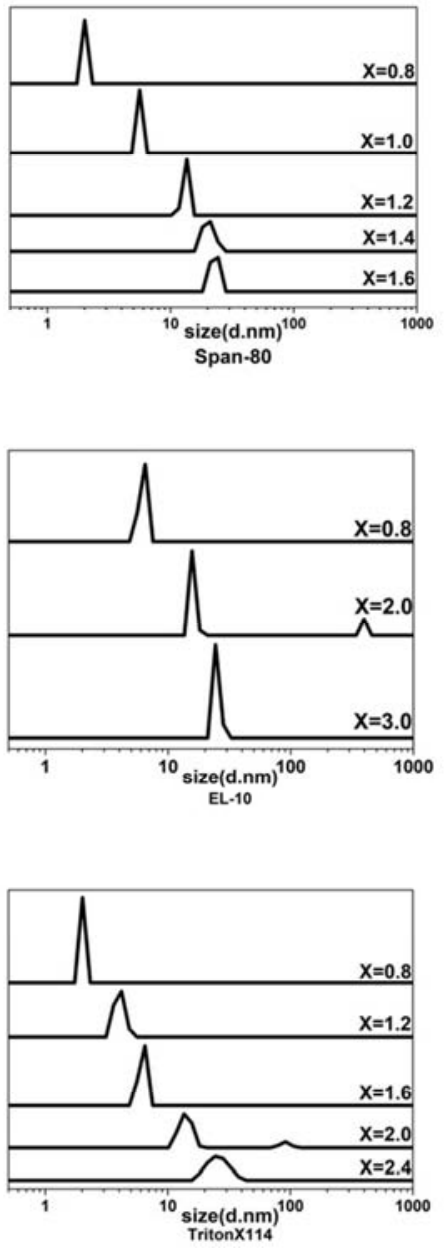

Figure 5. Size distributions of $\mathrm{O} / \mathrm{W}$ microemulsions droplets under different quality ratios of water to surfactant.

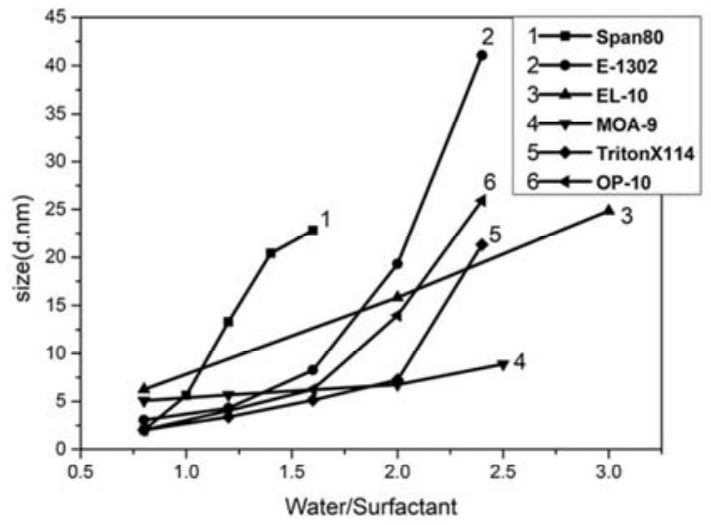

(a) microemulsions increases with the ratio of water to surfactant until a critical concentration is reached. This critical concentration is the start of the system destabilization. With further increasing the water amount, it will leave the monophasic region in the phase diagram and fail to form a stable microemulsion. The wide range of droplets size, from 1 $\mathrm{nm}$ to $120 \mathrm{~nm}$, is obtained with changing the surfactants and the ratios of water to surfactant.
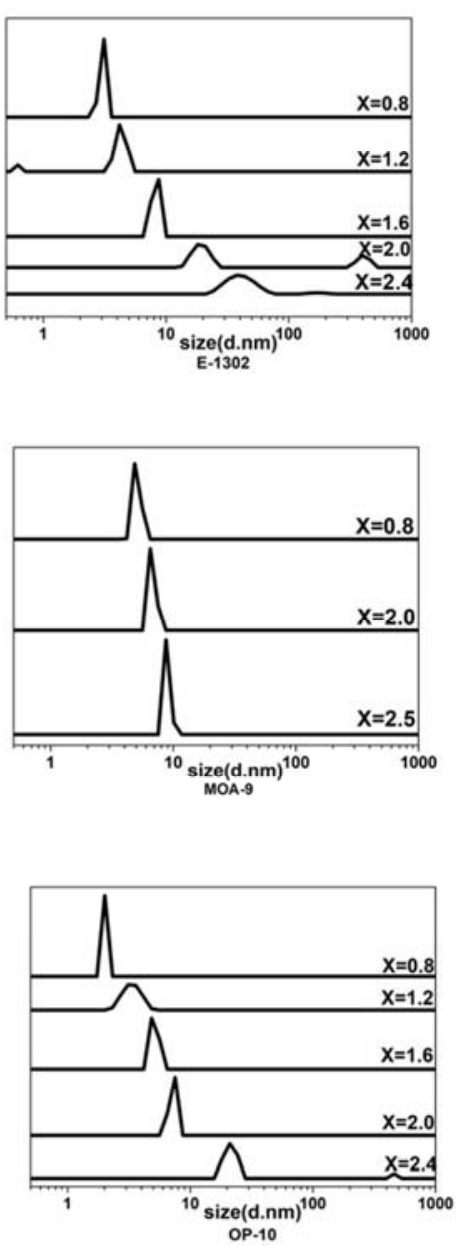

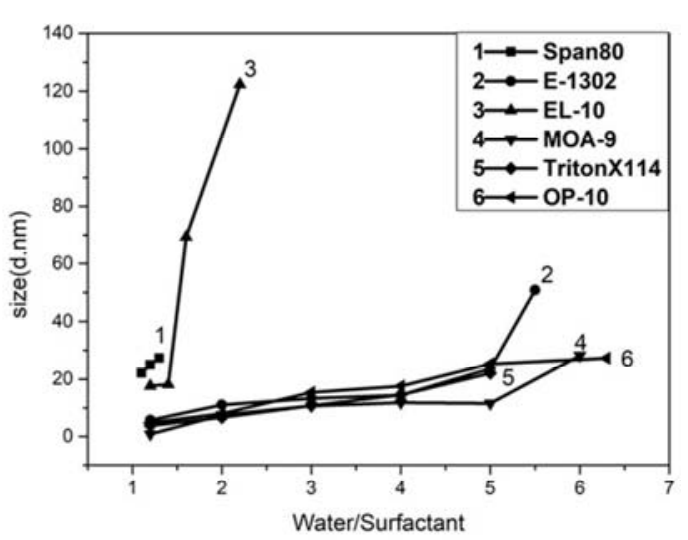

(b)

Figure 6. Microemulsions droplet size distribution with different surfactants and water to surfactant ratios, (a) and (b) represents the W/O and O/W micromulsions respectively. 
Figure 7 shows the influence of co-surfactant on the droplet size. Surfactant is EL-10 and the ratio of co-surfactant to surfactant is 3: 1 and 5: 1 respectively. It is obviously that the larger droplet size is obtained with increasing the co-surfactant amount. The largest droplet size even reaches the $122.4 \mathrm{~nm}$. The surfactant and co-surfactant molecules form interface film that separates the oil phase from the aqueous continues phase. The addition of co-surfactant further reduces the interfacial tension and therefore lowers the interfacial free energy which favors the formation of stable microemulsions and larger droplet $[17,18]$.

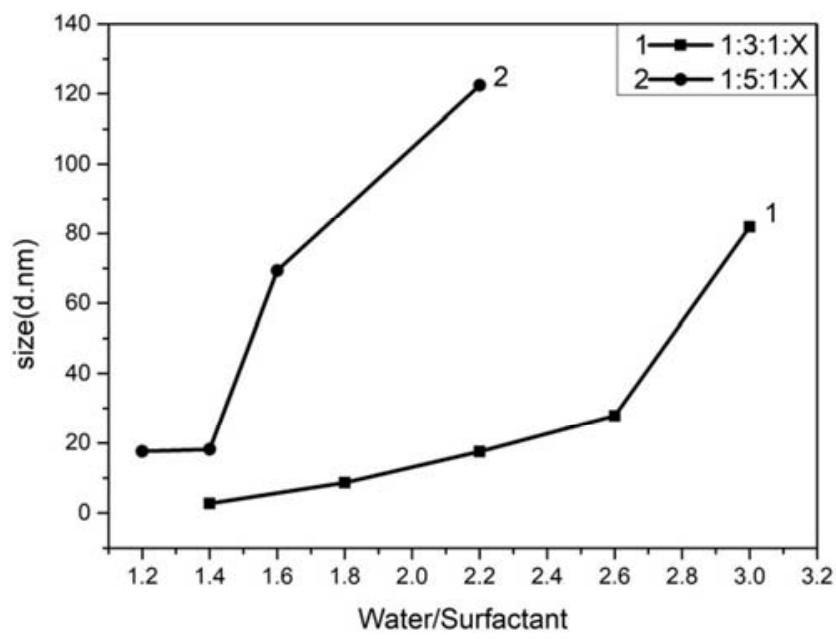

Figure 7. The droplet size of $\mathrm{O} / \mathrm{W}$ microemulsions with surfactant EL-10 as a function of water to surfactant ratio. The ration of co-surfactant to surfactant was 5:1 and 3:1 respectively.

\section{Conclusions}

Stable microemulsions were successfully obtained by titration method, and the quasi ternary phase diagrams of different surfactants were drawn based on lots of experimental data. The composition of surfactant/ co-surfactant/ oil/ water within the monophasic stable region can form the stable microemusions. The monophasic region area was not dependent on the titrant method.

The droplet size with narrow size distribution can be controlled in the wide range, from $1 \mathrm{~nm}$ to $120 \mathrm{~nm}$, by changing the surfactant type and composition. It showed a complex dependence of the droplet size on the water to surfactant ratio and the co-surfactant to surfactant ratio. In the stable microemulsions region, the droplets size increases dramatically with increased the water to surfactant ratio.

The results obtained in this work are the valuable reference for the synthesis of stable microemulsions and the controlling of the droplet size.

\section{Acknowledgements}

This work is financially supported by the Zhejiang Xinmiao Project, China (No. 2019R409012).

\section{References}

[1] J. Ma and B. Wu, Effect of surfactants on preparation of nanoscale $\alpha-\mathrm{Al}_{2} \mathrm{O}_{3}$ powders by oil-in-water microemulsion, Adv. Powder Technol. 24, 2013, 354-358.

[2] D. Buceta, Y. Piñeiro, C. Vázquez-Vázquez, J. Rivas and M. López-Quintela. Metallic Clusters: Theoretical Background, Properties and Synthesis in Microemulsions. Catalysts, 2014, 4 (4): 356-374.

[3] A. Nagy, J. P. Kennedy, P. Wang, C. Wesdemiotis and S. D. Hanton. Extent of coverage of surfaces treated with hydrophobizing microemulsions: A mass spectrometry and contact angle study. Applied Surface Science, 2006, 252 (10): 3751-3759.

[4] P. Brown, A. Mohamed, T. Ardyani, S. E. Rogers and J. Eastoe. Magnetic and Phase Behavior of Magnetic Water-in-Oil Microemulsions. Journal of Surfactants \& Detergents, 2017, 20: 1-6.

[5] V. Volpe, D. S. Nascimento, M. Insausti and M. Grünhut. Octyl p-methoxycinnamate loaded microemulsion based on Ocimum basilicum, essential oil. Characterization and analytical studies for potential cosmetic applications. Colloids \& Surfaces A Physicochemical \& Engineering Aspects, 2018 , 546: $285-292$.

[6] C. Souza C, L. A. Freitas. Topical Formulation Containing Beeswax-Based Nanoparticles Improved In Vivo, Skin Barrier Function. Aaps Pharmscitech, 2017, 18 (7): 1-12.

[7] D. Pepe, J. Phelps, K. Lewis, J. Dujack, K. Scarlett, S. Jahan, E. Bonnier, T. Milic-Pasetto, M. A. Hass and L. B. Lopes. Decylglucoside-based microemulsions for cutaneous localization of lycopene and ascorbic acid. International Journal of Pharmaceutics, 2012, 434 (1-2): $420-428$.

[8] S. Talegaonkar, A. Azeem, F. J. Ahmad, R. K. Khar, S. A. Pathan and Z. I. Khan. Microemulsions: a novel approach to enhanced drug delivery. Recent Patents on Drug Delivery \& Formulation, 2008, 2 (3): 238-295.

[9] D. Senatra, C. Gambi, A. Neri and M. Vannini. Depolarization Current Analysis and Electrical Birefringence in Water-in-Oil Microemulsions. Developments in Biophysical Research. Springer US, 1980: 195-206.

[10] N. Wang, L. Yang, L. Chen and R. Xiao. Study of the influence between magnesium ions and calcium ions on the morphology and size of coprecipitation in microemulsion. Surface Review \& Letters, 2014, 9 (5): 302-307.

[11] A. A. Derbina, A. V. Pirogov, I. D. Kargin and O. A. Shpigun. Application of water-in-oil microemulsions in microemulsion electrokinetic chromatography and as extractants of polar substances. Journal of Analytical Chemistry, 2015, 70 (10): 1271-1276.

[12] Y. Ren Y, Y. Zhao Y, Y. Zhang, W. Tang, X. Xin, J. Shen and L. Wang. Facile synthesis of Au@SiO 2, core-shell nanoparticles with multiple $\mathrm{Au}$ nanodots by a reverse microemulsion (water-in-oil) method. Colloids \& Surfaces A Physicochemical \& Engineering Aspects, 2015, 486: 14-20. 
[13] M. R. Kaiser, Z. Ma, X. Wang, F. Han, T. Gao, X. Fan, J. Z. Wang, H.K. Liu, S. and C. Wang. Reverse Microemulsion Synthesis of Sulfur/Graphene Composite for Lithium/Sulfur Batteries. Acs Nano, 2017, 11 (9): 9048.

[14] M. A. López-Quintela. Synthesis of nanomaterials in microemulsions: formation mechanisms and growth control. Current Opinion in Colloid \& Interface Science, 2004, 8 (2): 137-144.

[15] M. N. Krstajić Pajić, S. I. Stevanović, V. V. Radmilović, J. R. Rogan, V. R. Radmilović, S. L. Gojković and V. M. Jovanović. $\mathrm{Pt} / \mathrm{C}$ nanocatalysts for methanol electrooxidation prepared by water-in-oil microemulsion method. Journal of Solid State Electrochemistry, 2016, 20 (12): 3405-3414.
[16] R. Pichot, F. Spyropoulos and I. T. Norton. O/W emulsions stabilised by both low molecular weight surfactants and colloidal particles: The effect of surfactant type and concentration. J. Colloid Interface Sci 2010, 352: 128-135.

[17] T. Charinpanitkul, A. Chanagul, J. Dutta, U. Rungsardthong and W. Tanthapanichakoon, Effects of cosurfactant on $\mathrm{ZnS}$ nanoparticle synthesis in microemulsion, Sci Technol Adv Mat, 6, 2005 266-271.

[18] H. Araya, M. Tomita and M. Hayashi. The novel formulation design of $\mathrm{O} / \mathrm{W}$ microemulsion for improving the gastrointestinal absorption of poorly water soluble compounds. Int J Pharm. 2005, 305 (1-2): 61-74. 